\title{
Estimating Carbon Dioxide and Particulate Matter Emissions from Ships using Automatic Identification System Data
}

\author{
Arnélio Sérgio Mabunda \\ Laboratoire d'Informatique, \\ Systèmes et \\ Télécommunications \\ Faculté des Sciences et \\ Techniques - Université \\ Abdelmalek Essaadi \\ Ancienne Route de l'Aéroport, \\ Km 10, Ziaten. BP: 416. Tanger \\ - Maroc
}

\author{
Abdelali Astito \\ Laboratoire d'Informatique, \\ Systèmes et \\ Télécommunications \\ Faculté des Sciences et \\ Techniques - Université \\ Abdelmalek Essaadi \\ Ancienne Route de l'Aéroport, \\ Km 10, Ziaten. BP: 416. Tanger \\ - Maroc
}

\author{
Salaheddine Hamdoune \\ Laboratoire d'Informatique, \\ Systèmes et \\ Télécommunications \\ Faculté des Sciences et \\ Techniques - Université \\ Abdelmalek Essaadi \\ Ancienne Route de l'Aéroport, \\ $\mathrm{Km}$ 10, Ziaten. BP: 416. Tanger \\ - Maroc
}

\begin{abstract}
This paper proposes a method for estimating emissions of carbon dioxide $\left(\mathrm{CO}_{2}\right)$ and particulate matter (PM) from ships using Automatic Identification System (AIS) data. The method can be summarized in three steps : 1) capture of AIS data, 2) estimation of ships resistance, propulsion power, engine power and fuel consumption, 3) estimation of $\mathrm{CO}_{2}$ and PM emissions based on fuel consumption.

The method has been developed to carry out a computer application for monitoring in real-time $\mathrm{CO}_{2}$ and $\mathrm{PM}$ emissions from ships sailing in the Strait of Gibraltar. A system for receiving AIS data broadcasted by ships sailing in the Strait of Gibraltar has been installed.
\end{abstract}

\section{Keywords}

Maritime pollution, Strait of Gibraltar, AIS data, ships, realtime system

\section{INTRODUCTION}

The Strait of Gibraltar is an important shipping route for merchant and passenger ships, this is one of the most used sea lanes in the world. It is difficult to have an exact number of maritime traffic in this region because there is no authority or observatory to this statistic [1], but some sources claim that about 100000 ships cross the Strait each year.

Ships emit exhaust gases in the atmosphere and some of these gases are harmful to the environment in general. We believe that it's important to know and monitor the level of pollution caused by the maritime traffic in this region, especially that of carbon dioxide $\left(\mathrm{CO}_{2}\right)$ and particulate matter $(\mathrm{PM}) . \mathrm{CO}_{2}$ and $\mathrm{PM}$ are known respectively as greenhouse gas [2] and carcinogenic dust [3].
Some papers propose methods for estimating $\mathrm{CO}_{2}$ and PM emissions from ships using Automatic Identification System (AIS) data in Baltic Sea [4] or in Madura Strait area [5], but there is no papers related to the strait of Gibraltar. Furthermore, these methods do not take into account real-time emissions. The purpose of the method presented in this paper is to use AIS data to establish a maritime monitoring system to estimate in real time $\mathrm{CO}_{2}$ and $\mathrm{PM}$ emissions from ships sailing in the strait of Gibraltar.

This method is largely based on the mathematical formulas used in the naval architecture. This method does not take into account ships moored or berthed in ports. Furthermore, the method evaluates only the emissions produced by the main engine, excluding auxiliary engines and boilers.

\section{MATERIALS AND METHODS}

\subsection{AIS data}

Automatic Identification System (AIS) is a telecommunication system used on ships and by vessel traffic services for exchanging data with other nearby ships and AIS base stations. Data transmission is done through electromagnetic waves VHF (Very High Frequency). The AIS sends static data such as Maritime Mobile Service Identity (MMSI), length overall, breadth, draught (height of the ship's submerged portion), ship type, ship name, etc. The system provide also dynamic data such as speed, geographical position, direction, destination, etc.. Dynamic data is sent every 2 to 10 seconds and static data is sent every 6 minutes. Since 2004, the International Convention for the Safety of Life at Sea (SOLAS) [6] requires that all vessels greater than 300 tons gross tonnage engaged on international voyages to be fitted with AIS.

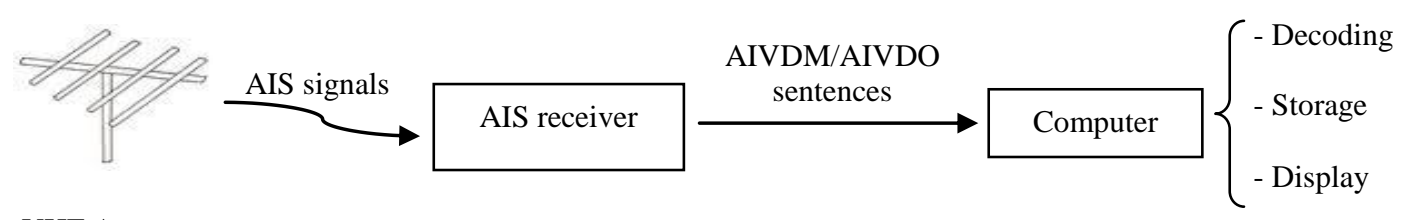

VHF Antenna

Fig 1: The installed AIS receiving system 
A system for receiving AIS data has been installed in LIST laboratory (Laboratoire d'Informatique, Systèmes et des télécommunications). The system consists of an AIS receiver, a VHF antenna and a computer for data collection and display (Figure 1).

\subsection{Overview of the installed AIS receiving system}

The AIS receiver is connected to computer through RS232 connector and data is transmitted to computer in AIVDM/AIVDO sentences [7]. In the computer, we developed a program that decodes, stores on database and displays data on a map (Figure 2). The decoding AIVDM/AIVDO sentences algorithm was based on the guidelines of the document [7].

This system operates in real time and covers the western side of the Strait of Gibraltar and the northern side of the Moroccan Atlantic coast (Figure 2). The program graphical user interface (GUI) displays static and dynamic data related to ships detected (Figure 2).

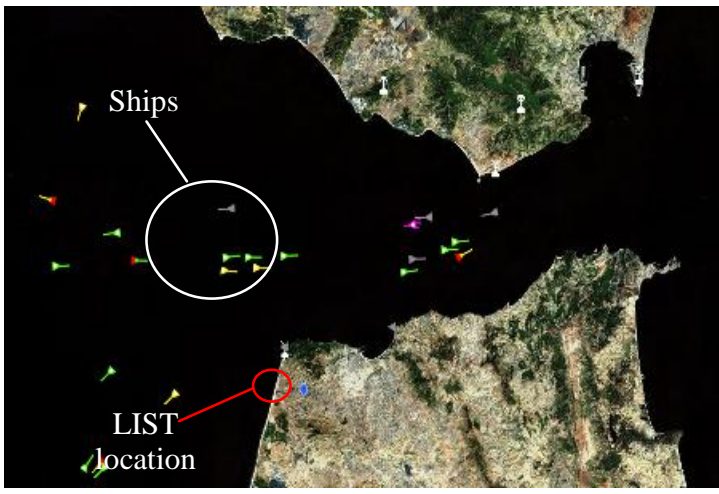

Fig 2: Screenshot of the program GUI showing ships sailing in the Strait of Gibraltar. This screenshot was taken on $10^{\text {th }}$ January 2014

The system developed records the crossing of 140 ships per day average of which 56\% are cargo ships, $20 \%$ tanker ships, $4 \%$ passenger ships, $5 \%$ other types of ships and $15 \%$ ships unidentified (Figure 3).

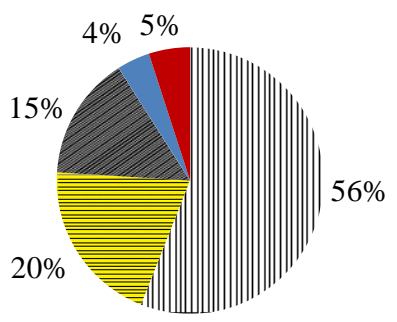

$$
\begin{aligned}
& \text { - Cargo } \\
& \text { = Tanker } \\
& \text { - Unidentified } \\
& \text { - Passenger } \\
& \text { - Other types }
\end{aligned}
$$

Fig 3: Sample of daily average traffic recorded by the system between $10^{\text {th }}$ and $24^{\text {th }}$ December 2013

\subsection{Proposed method for estimating $\mathrm{CO}_{2}$ and PM emissions}

In order to evaluate the $\mathrm{CO}_{2}$ and $\mathrm{PM}$ emissions, four data have to be estimated : ship resistance, propulsion power, main engine power and fuel consumption. Figure 4 summarizes the steps in the model to estimate $\mathrm{CO}_{2}$ and $\mathrm{PM}$ emissions using AIS data.

\subsubsection{Ship resistance $\left(R_{T}\right)$}

According to the International Towing Tank Conference (ITTC) [8], ship resistance is defined by :

$$
\mathrm{RT}=\frac{1}{2} \cdot C_{T} \cdot \rho \cdot S \cdot V^{2}
$$

Where: $\mathrm{C}_{\mathrm{T}}$ is the total resistance coefficient, $\mathrm{S}$ is the wetted surface area of the hull, $\mathrm{V}$ is the ship navigation speed and $\rho$ is the mass density of water.

To determine the wetted surface area $(\mathrm{S})$, we used the Mumford's formula [9].

$$
S=1.025 \cdot L \cdot\left(C_{b} \cdot B+1.7 \cdot T\right)
$$

Where: $\mathrm{C}_{\mathrm{b}}$ is the block coefficient, $\mathrm{T}$ and $\mathrm{B}$ are respectively draught and breadth and $\mathrm{L}$ is the length on waterline.

The $C_{b}$ value depends on the hull shape, for example, full forms such as oil tankers have a high $\mathrm{C}_{\mathrm{b}}$, where fine shapes such as sailboats have a low $C_{b}[10]$. $L$ can be determined according to the following formula [11]:

$$
L=\frac{L O A}{1.05} ; \quad\left(\mathrm{L}_{\mathrm{OA}}-\text { length overall }\right)
$$

The total resistance coefficient $\left(\mathrm{C}_{\mathrm{T}}\right)$ is determined by [8] :

$$
C_{T}=C_{F}+C_{R}+C_{A}+C_{A A}
$$

Where: $C_{F}$ is the frictional resistance coefficient, $C_{R}$ is the residual resistance coefficient, $\mathrm{C}_{\mathrm{A}}$ is the incremental resistance coefficient, $\mathrm{C}_{\mathrm{AA}}$ is the air resistance coefficient.

The $\mathrm{C}_{\mathrm{A}}$ and $\mathrm{C}_{\mathrm{AA}}$ values depend on the size of the ship [11, 12, 13]. The $C_{R}$ coefficient includes wave resistance, the viscous pressure resistance, and the additional resistance due to the form or curvature of the hull [12]. The frictional resistance coefficient $\left(\mathrm{C}_{\mathrm{F}}\right)$ is determined by [14] :

$$
C_{F}=\frac{0.075}{\left(\log _{10} R n-2\right)^{2}}
$$




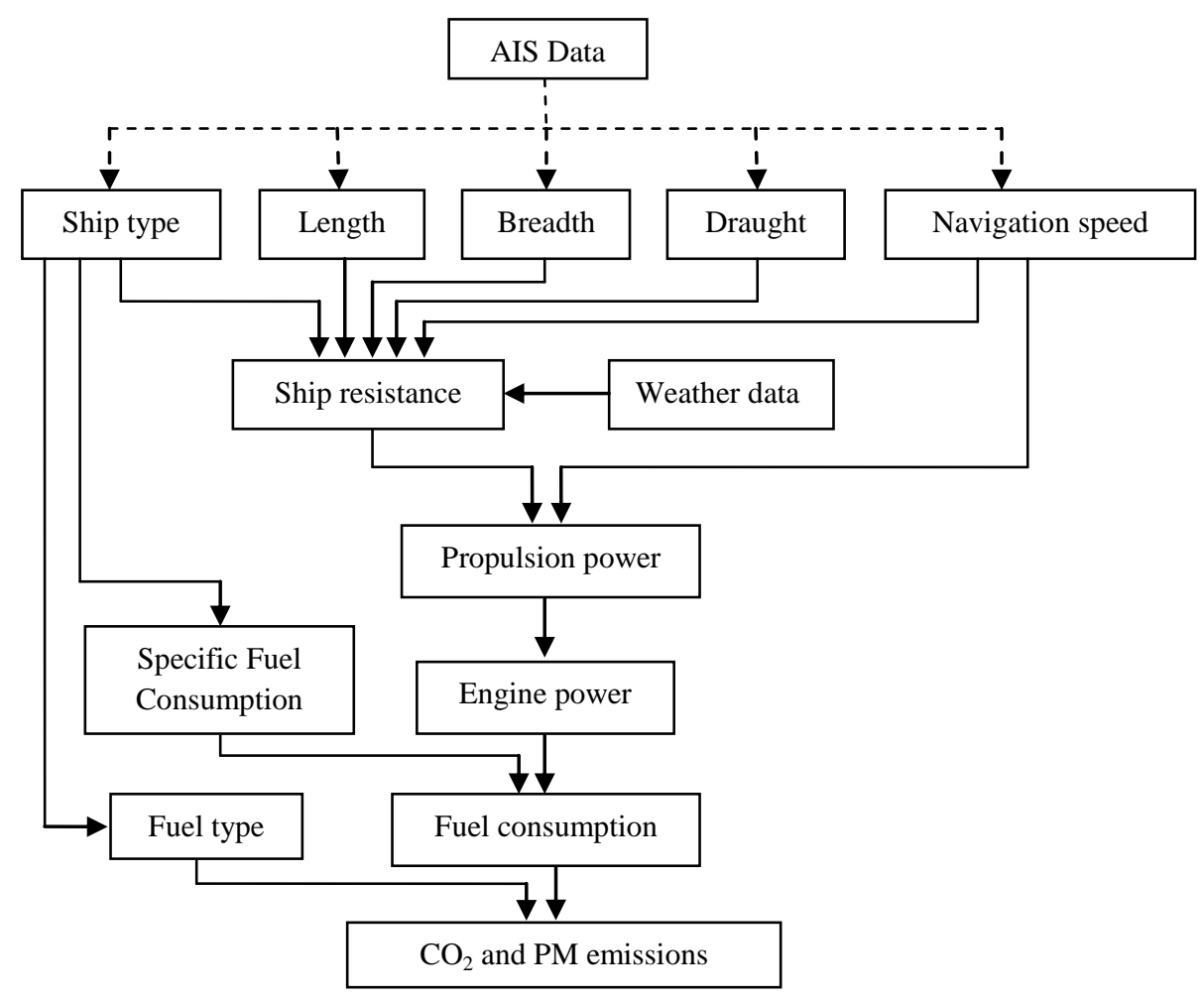

Fig 4: The Model diagram

Where: $R_{n}$ is the Reynolds number [14] (ratio between the inertial forces and viscous forces).

$$
R n=\frac{V \cdot L}{v} ;(v-\text { kinematic viscosity })
$$

Guldhammer and Harvald [13] developed an empirical method for residual resistance coefficient prediction. $C_{R}$ is presented as function of the prismatic coefficient $\left(C_{P}\right)$ [10], length-displacement ratio $(\mathrm{M})$ and Froude number $\left(\mathrm{F}_{\mathrm{N}}\right)$. For example, for $M=4.5, C_{P}=0.7, C_{R}$ is given by:

$$
\begin{aligned}
& C_{R}=\left(8196395967 \cdot{F_{N}}^{5}-6937212684{F_{N}}^{4}+\right. \\
& 2370028578 \cdot F_{N}{ }^{3}-401665661 \cdot F_{N}{ }^{2}+ \\
& \left.339.10948 \cdot F_{N}-10.91\right) \cdot 10^{-3}
\end{aligned}
$$

The $C_{R}$ is given without correction for hull form or bulbous bow. Harvald gives additional correction for these parameters $[12,13]$.

The length-displacement ratio (M) is determined by [12] :

$$
\begin{gathered}
M=\frac{L}{\sqrt[3]{\nabla}} \\
\nabla=L \cdot B \cdot T \cdot C b ; \quad(\nabla-\text { displacement })
\end{gathered}
$$

The Froude number $\left(\mathrm{F}_{\mathrm{N}}\right)$ is determined by [14] :

$$
F_{N}=\frac{V}{\sqrt{g \cdot L}} ; \quad(\mathrm{g}-\text { gravity constant })
$$

\subsubsection{Propulsion power $\left(P_{P}\right)$}

The propulsion power is the product of speed $(\mathrm{V})$ and ship resistance $\left(R_{T}\right)$. The $R_{T}$ is initially determined without taking into account the weather conditions at sea (sea state, wind and tidal currents), consequently to compensate the weatherrelated strengths, the parameter Service Allowance (SA) is added [12].

$$
P_{p}=V \cdot R_{T} \cdot\left(1+\frac{S A}{100}\right)
$$

The Service Allowance (SA) is a parameter given in \% and used to compensate the weather-related strengths at sea. Its value is set according to the navigation area. Harvald [13] proposes values on the following table :

Table 1. Service Allowance values according to Harvald

\begin{tabular}{|l|c|c|}
\hline \multirow{2}{*}{\multicolumn{1}{|c|}{ Navigation area }} & \multicolumn{2}{c|}{$\begin{array}{c}\text { Service Allowance } \\
\text { (SA) }\end{array}$} \\
\cline { 2 - 3 } & Summer & winter \\
\hline $\begin{array}{l}\text { North Atlanctic route, } \\
\text { westbound }\end{array}$ & $25 \%$ & $35 \%$ \\
\hline $\begin{array}{l}\text { North Atlantic, } \\
\text { eastbound }\end{array}$ & $20 \%$ & $25 \%$ \\
\hline Europe - Australia & $20 \%$ & $25 \%$ \\
\hline Europe - Eastern Asia & $20 \%$ & $25 \%$ \\
\hline The Pacific routes & $20 \%$ & $30 \%$ \\
\hline
\end{tabular}

These figures are only rough figures, which can be used for guidance. In this paper, we used values assigned to the "North Atlantic, eastbound". 


\subsubsection{Engine power $\left(P_{E}\right)$}

The power produced by the engine of a ship is never completely converted into propulsion power [9], there is in fact a power loss at the transmission system. The power of engine required to move a ship at speed $\mathrm{V}$, is defined as the ratio between the propulsion power $\left(\mathrm{P}_{\mathrm{P}}\right)$ and performance of the transmission system $(\eta)$.

$$
P E=\frac{P_{p}}{\eta}
$$

According to Schneekluth [11], the transmission system performance in ships ranges between 0.4 and 0.7 . The average value $(\eta=0.55)$ was used in this paper.

Note : Some ships use multiple engines for propulsion, the value of $P_{E}$ represents in this case the power produced by all propulsion engines.

\subsubsection{Fuel consumption}

Fuel consumption $(\mathrm{CON})$ is the product of the engine power $\left(\mathrm{P}_{\mathrm{E}}\right)$ and the specific fuel consumption (SFC).

$$
C O N=P_{E} \cdot S F C
$$

Specific fuel consumption (SFC) is the fuel consumption compared to the work done and is commonly expressed in $\mathrm{g} / \mathrm{kW} \cdot \mathrm{h}$ [15]. The SFC depends on a range of parameters including engine size, age and the energy density of the fuel. The International Maritime Organization (IMO) [15] published data about SFC (table 2).

Table 2. Typical values of specific fuel consumption for engines built between years 2001 and 2007 according to IMO

\begin{tabular}{|l|c|}
\hline \multicolumn{1}{|c|}{ Engine type } & $\begin{array}{c}\text { Specific fuel } \\
\text { consumption in } \\
\text { g/kWh }\end{array}$ \\
\hline 2 stroke low speed & $165-175$ \\
\hline $\begin{array}{l}4 \text { stroke medium - high speed } \\
(>5000 \mathrm{~kW})\end{array}$ & $175-185$ \\
\hline $\begin{array}{l}4 \text { stroke medium - high speed } \\
(1000-5000 \mathrm{~kW})\end{array}$ & $180-200$ \\
\hline $\begin{array}{l}4 \text { stroke medium - high speed } \\
(<1000 \mathrm{~kW})\end{array}$ & $190-230$ \\
\hline
\end{tabular}

In [15], IMO gives a table linking ship type, main engine size and fuel type used by the engine.

\subsubsection{Carbon dioxide and particulate matter emissions}

To determine the $\mathrm{CO}_{2}$ and $\mathrm{PM}$ emissions from the engine, we used the following formula :

$$
\text { Gas_Emissions }=\text { Emission_Factor } \cdot \text { CON }
$$

The "Gas_Emissions" is the amount of $\mathrm{CO}_{2}$ or $\mathrm{PM}$ emitted by the engine, "Emission_Factor" is the $\mathrm{CO}_{2}$ or PM emission factor. The emission factor (Table 3 ) is given in kilograms per tonne of fuel $(\mathrm{kg} / \mathrm{t})[15,16,17]$.
Table 3. Emission factor according to IMO

\begin{tabular}{|c|l|c|}
\hline \multirow{2}{*}{ Gas } & Fuel type & $\begin{array}{c}\text { Emission factor } \\
\text { in kg/t }\end{array}$ \\
\hline \multirow{2}{*}{$\mathrm{CO}_{2}$} & Marine diesel oil & 3206 \\
\cline { 2 - 3 } & Heavy fuel oil & 3114.4 \\
\hline \multirow{2}{*}{$\mathrm{PM}$} & Marine diesel oil & 1.1 \\
\cline { 2 - 3 } & Heavy fuel oil & 6.7 \\
\hline
\end{tabular}

\section{PRACTICAL EXAMPLE}

To check the results given by the method, we applied it on a ship. The ship characteristics (Table 4) are the same used by Watson in [9]. This data (Table 4) is similar to that provided by a ship through the AIS system.

\section{Tab 4. ship characteristics}

\begin{tabular}{|c|c|}
\hline Ship type & Tanker \\
\hline Length & $156.65 \mathrm{~m}$ \\
\hline Breadth & $25.06 \mathrm{~m}$ \\
\hline Draught & $9.47 \mathrm{~m}$ \\
\hline Navigation speed & $15 \mathrm{knots}$ \\
\hline
\end{tabular}

\subsection{Main engine power}

To check the values given by the method presented in this paper when calculating the propelling power, the results were compared with those of Watson (table 5).

Tab 5. Estimating main engine power

\begin{tabular}{|l|c|c|}
\hline \multirow{2}{*}{\multicolumn{1}{|c|}{ Parameter }} & \multicolumn{2}{|c|}{ Results } \\
\cline { 2 - 3 } & $\begin{array}{c}\text { Watson's } \\
\text { method }\end{array}$ & Our method \\
\hline $\begin{array}{l}\text { Wetted surface area of } \\
\text { the hull }(\mathrm{S})\end{array}$ & $5528 \mathrm{~m}^{2}$ & $5602.8 \mathrm{~m}^{2}$ \\
\hline $\begin{array}{l}\text { Total resistance } \\
\text { coefficient }\left(\mathrm{C}_{\mathrm{T}}\right)\end{array}$ & $2.5 \cdot 10^{-3}$ & $2.998 \cdot 10^{-3}$ \\
\hline $\begin{array}{l}\text { Propulsion power } \\
\text { excluding weather } \\
\text { conditions }\end{array}$ & $3254 \mathrm{~kW}$ & $3945.5 \mathrm{~kW}$ \\
\hline $\begin{array}{l}\text { Propulsion power }\left(\mathrm{P}_{\mathrm{P}}\right) \\
\text { taking into account } \\
\text { weather conditions }\end{array}$ & - & $4833.2 \mathrm{~kW}$ \\
\hline Engine power $\left(\mathrm{P}_{\mathrm{E}}\right)$ & - & $8787.6 \mathrm{~kW}$ \\
\hline
\end{tabular}

\section{2 $\mathrm{CO}_{2}$ and PM emissions}

The estimated engine power allows estimate the fuel consumption according to the relation (4). The $\mathrm{CO}_{2}$ and PM emissions are based on fuel type and fuel consumption and given in kilogram per minute (table 6).

Table 6. $\mathrm{CO}_{2}$ and $\mathrm{PM}$ emissions from the engine

\begin{tabular}{|l|c|}
\hline \multicolumn{1}{|c|}{ Parameter } & Results in kg/min \\
\hline Fuel consumption & 27.1 \\
\hline $\mathrm{CO}_{2}$ emissions & 84.4 \\
\hline $\mathrm{PM}$ emissions & 0.18 \\
\hline
\end{tabular}




\section{DISCUSSION}

Table 5 shows that the results given by both methods are similar. The method presented in this paper takes into account the weather conditions at sea (North Atlantic, eastbound) while that of Watson ignores them. The differences in the wetted surface area and the residual resistance coefficient results are mainly due to the fact that the method presented here uses respectively Mumford and Harvald's formulas [9, $12,13]$ to determine these parameters, while Watson's method uses Taylor and ITTC's formulas [9]. The propulsion power results (excluding weather conditions) depend on these parameters.

\section{CONCLUSION}

The method described in this work allows the estimation of $\mathrm{CO}_{2}$ and $\mathrm{PM}$ emissions from ships using AIS data. The results depend on parameters such as the ship type, navigation speed and ship proportions. Another parameter taken into account is the influence of the weather conditions at sea on ships, that somehow affects fuel consumption and therefore $\mathrm{CO}_{2}$ and $\mathrm{PM}$ emissions. This method integrated into a computer application and linked to the system receiving AIS data allows estimate the $\mathrm{CO}_{2}$ and $\mathrm{PM}$ emissions from ships in real time. Data can be stored in a database and used for statistical analysis in order to monitor the rate of $\mathrm{CO}_{2}$ and $\mathrm{PM}$ emissions caused by ships sailing in the Strait of Gibraltar.

\section{REFERENCES}

[1] Nora MAREI, "Enjeux maritimes et portuaires du détroit de Gibraltar", Institut Supérieur d'Economie Maritime, ISSN : 1282-3910, Mai 2008

[2] J. T. Kiehl et Kevin E. Trenberth, "Earth's Annual Global Mean Energy Budget", Bulletin of the American Meteorological Society, vol. $78, n^{\circ} 2$, p. 197-208, February 1997.

[3] World Health Organization, "Health risks of particulate matter from long-range transboundary air pollution", WHO Regional Office for Europe, Denmark, 2006, available

at: http://www.euro.who.int/_data/assets/pdf_file/0006/786 57/E88189.pdf

[4] J.-P. Jalkanen et Al., "Extension of an assessment model of ship traffic exhaust emissions for particulate matter and carbon monoxide", Atmospheric Chemistry and Physics, doi:10.5194/acp-12-2641-2012, 12 March 2012.

[5] Trika Pitana et Al., «Estimation of Exhaust Emissions of Marine Traffic Using Automatic Identification System Data (Case Study: Madura Strait Area, Indonesia) », IEEE, 2010.
[6] SOLAS'1974, December 2000 amendments, available at: http://www.imo.org/KnowledgeCentre/ReferencesAndAr chives/HistoryofSOLAS/Documents/SOLAS\%201974\% 20-\%20Brief\%20History\%20$\% 20$ List $\% 20$ of $\% 20$ amendments $\% 20$ to $\% 20$ date $\% 20$ and $\% 20$ how\%20to\%20find\%20them.html\#43

[7] Eric S. Raymond, "AIVDM/AIVDO protocol decoding", version 1.32, June 2011, available at: http://gpsd.berlios.de/AIVDM.txt

[8] International Towing Tank Conference (ITTC), "Performance, Propulsion 1978 ITTC Performance Prediction Method", ITTC - Recommended Procedures and Guidelines, Section 7.5 - $02-03$ - 01.4, Revision 00, 1999.

[9] Watson D. G. M., "Practical Ship Design", Elsevier Ocean Engineering Book Series, volume 1, ISBN: 0-08-042999-8, Oxford, UK, 1998.

[10] Dominique Paulet et Dominique Presles, "Architecture navale, connaissance et pratique", Éditions de la Villette, ISBN : 2-903539-46-4, 1999.

[11] Schneekluth, H. and Bertram, "Ship Design for Efficiency and Economy", Butterworth-Heinemann, Second edition, ISBN 075064133 9, 1998.

[12] Hans Otto Kristensen \& Marie Lützen, "Prediction of Resistance and Propulsion Power of Ships", Technical University of Denmark \& University of Southern Denmark, Project no. 2010-56, Work Package 2, Report no. 04, October 2012.

[13] Harvald S. A., "Resistance and Propulsion of Ships", Wiley, ISBN 0-89464-754-7, 1983.

[14] International Towing Tank Conference (ITTC), "Testing and Extrapolation Methods Resistance, Resistance Test", ITTC - Recommended Procedures and Guidelines, Section 7.5-02-02-01, Revision 01, 2002.

[15] International Maritime Organization, "Second IMO GHG Study 2009", CPI Books Limited, Reading RG1 8EX, London, UK, April 2009, available at: http://www.imo.org/blast/blastDataHelper.asp?data_id=2 7795\&filename $=$ GHGStudyFINAL.pdf

[16] International Maritime Organization, "Interim Guidelines on the Method of Calculation of the Energy Efficiency Design Index for New Ships", Ref. T5/1.01, MEPC.1/Circ.681, London, 17 August 2009.

[17] Ernestos Tzannatos, "Ship emissions and their externalities for Greece", Atmospheric Environment, doi:10.1016/j.atmosenv.2010.03.018, 2010. 